\title{
CREATING PERSONAS FOR POLITICAL AND SOCIAL CONSCIOUSNESS IN HCI DESIGN
}

\author{
Anna Wilson, Stefano De Paoli, Paula Forbes and Marco Sachy
}

\begin{abstract}
Personas have become an important tool for Human-Computer Interaction professionals. However, they are not immune to limitations and critique, including stereotyping. We suggest that while some of the criticisms of personas are important, the use of personas is open to them in part because of an unquestioned focus on explicating user needs and goals in traditional persona research and creation.

This focus, while helping designers, obscures some other potentially relevant aspects of persona creation and use. In particular, when the goal of the product or software being designed is associated with social and political goals rather than with bringing a product to the market, it may be relevant to focus personas on political aspirations, social values and the will or capacity of personas to take action. We argue that it is possible when producing personas (and associated scenarios) to partially move away from representing needs and embrace personas which more explicitly represent political or social beliefs and values. We also suggest that a phenomenographic approach to user data analysis is one way to achieve this. We provide empirical evidence for our position from two large-scale European projects, the first one in the area of Social Innovation and the second in the area of eParticipation.
\end{abstract}

\section{KEY WORDS}

Personas; Phenomenography; Values; Difference; Possibility; Action

\section{INTRODUCTION}

Design personas have become an increasingly popular tool intended to help Human-Computer Interaction (HCI) professionals reflect on and design for the potential users of their products (Cooper et al. 2007; Pruitt and Grudin 2003). Ideally based on empirical research, personas, and the narrative scenarios that accompany them, are intended to synthesise the needs and goals of different possible users (Cooper 2004) and to illustrate the likely nature of interactions with the technological artefact being designed. The principle underpinning personas is that the user's use of the product/service is the basis on which that product/service should be designed (Cooper et al. 2007; Rogers et al. 2007). This perspective breaks with traditional top-down approaches to requirements gathering in software engineering, such as the Waterfall or Spiral models, where user requirements are defined via top level engineering representations (Avison and Fitzgerald 2003). In contrast, personas, as archetypes of likely users, are used to help designers make decisions around user needs and their social contexts. By naming and giving a face to potential users, and providing contextual details of lived experiences, personas also encourage technical and design teams to develop empathy (Cooper 2004; Pruitt and Grudin 
2003). As such, personas have become an important element of 'user-centred' design approaches (Rosenfeld and Morville 2002; Nielsen 2003) and are finding their way into software projects adopting participatory (Shuler and Namioka 1993) and lean (Gothelf and Seiden 2013) design approaches.

However, design personas have recently been subject to some critique, ranging from their inevitable collapsing of highly-varied individuals into broad categories that easily slips into stereotyping, to their status as boundary objects that can actually serve to distance designers from users and their politically-loaded function within design teams (e.g., Massanari 2010; Turner and Turner 2011).

In this article, we suggest that while some of these criticisms are important, they arise in part because of an unquestioned focus on explicating user needs and goals. While this may be appropriate in contexts where HCI professionals are designing products for commercial purposes, it may not be appropriate in other contexts, such as those in which the social value of the designed artefact is more important than its market function. For example, when the artefact has a socio-political function with a social justice or sustainability orientation (such as a system that promotes community or environmental awareness), it may be more important to create personas that illustrate potential users' values, desire for emancipation, philosophies and/or political beliefs, and willingness/capacity to take action. This may be particularly important in creating the kind of empathy in designers that will allow them to create artefacts that are congruent with and support users to act according to these beliefs. In other words, we argue that in some contexts, those involved in researching and creating personas might need to shift the emphasis away from the representation of needs, and embrace personas which more explicitly represent political or social beliefs.

We suggest that phenomenography (Marton 1981), an analytical approach developed in educational studies but that can be applied in broader contexts to explore variation in concrete experiences as well as conceptual understandings, may be an effective way of surfacing and articulating such values and beliefs. We show how phenomenography can be translated to the field of HCI in order to build personas. We provide empirical evidence for our position from two large-scale European projects. The first aims to facilitate complementary, bottom-up approaches to social welfare for people experiencing poverty and precarious social and financial conditions. In this case, persona development has emphasised the desire for dignity and emancipation, and the capacity for action of personified users (Wilson et al. 2017). The second involves persona development in the design of digital platforms intended to foster young people's engagement with environmental policy making (Vogiatzi et al. 2017). In this case, development of personas has emphasised breaking the barrier of mistrust that exists between young people and policy makers, and the capacity to take action for the environment.

In the following, we first present a brief overview of the persona method and significant criticisms. We then describe our work in these two projects, including the phenomenographic approach to data analysis, in order to show how we arrived at our position regarding the need to create personas that emphasise values and capacity.

\section{PERSONAS IN HCI DESIGN: AN OVERVIEW AND CRITIQUE}

The creation of personas intended to inform the design of technological artefacts has become widespread in the field of HCI (Cooper et al. 2007). Usually created in the form of short text pieces accompanied by a photographic image, they provide designers and engineers with a quick, engaging connection with potential users of the technologies they are working on. 
The development of personas traditionally starts with qualitative, inductive empirical research, such as ethnography or qualitative interviews, into intended or potential users of the technology being designed. Qualitative approaches support the exploration and identification of new ideas and insights for the design of new products and services (Cooper et al. 2007). This user research also focuses on revealing what users say and do (Mulder and Yaar 2006), with the goal of identifying patterns in motivations, actual behaviours, activities, frustrations, and skills, and involves collecting data on and with target user groups.

Personas are 'user archetypes' that help ensure that decisions about design solutions are informed by a user-driven perspective. Personas "are not actual people but are synthesized directly from observations of real people" (Cooper et al. 2007, p. 81). Personas are models of real users whose traits "are identified through the analysis of interview data" (ibid., p. 82). Scenarios are narratives that describe the personas interacting with the future product or service. Capturing the user perspective, scenarios deliver an array of potential advantages (Carroll 2000) such as enabling designers to imagine plausible and feasible solutions to user needs or focus on actual user activities in a real situation, rather than on abstract assumptions about user behaviour that are not based on empirical evidence.

The use of personas has undoubtedly increased designers' awareness of and sense of connection with the potential users of the artefacts and technologies they design. However, they also bring to light and possibly create new problems with implementing genuinely user-centred design processes. Recently, criticisms of persona-based approaches have been raised by several authors. For example, despite the widespread belief among HCI experts reported by Marsden and Haag (2016) that anyone can use the persona method, accurate, representative persona construction is not trivial. Some authors have noted a tendency for designers to construct personas that reflect their own, rather than their potential users' preferences (Floyd et al. 2008). Gudjonsdottir (2010) and Matthews et al. (2012) found that designers sometimes find personas abstract and impersonal: in an attempt to counter this, Anvari and Tran (2013) suggest the use of what they term Holistic Personas, which include a personality element as well as factual and cognitive dimensions. However, the incorporation of a somewhat psychologised version of personality (Anvari et al. 2017) may not avoid another key problem - that of stereotyping (Marsden and Haag 2016; Turner and Turner 2011).

Turner and Turner's (2011) work focuses on "the tension between the economy of stereotyping on the one hand and the potential for bias and loss of rich detail on the other" ( $p$. 30). They identify this as an important issue because, "as widely discussed in science and technology studies ... designs inscribe cultural values and notions of ideal users. Such values in turn prescribe and shape everyday activities and expectations" (ibid., emphasis in original). Noting that "the power of stereotypes lies with their cognitive economy ... that is, their use allows us to assess, sum up and engage with a situation with the minimum of cognitive effort" (ibid., p. 36), they caution that stereotypes have an "insidious quality" (ibid.) in that they can lead us to immediate and, perhaps, lazy and unjustified assumptions and generalizations. Such assumptions and generalizations can then "serve a discursive and social purpose in legitimating design arguments and 'pet' design features and softening refutations of others' contributions" (ibid., p. 37). Personas, perceived as stereotypes of objectified consumers, could actually decrease designers' engagement and empathetic connection with the target user group.

On a related issue, Chapman and Milham (2006) suggest that personas are not actually effective or accurate ways of communicating data. They identify three key problems: the nonverifiability of fictional constructions, a problematic relationship between personas and actual user populations, and difficulties with inference from highly-specific personas to 
understandings of use by those actual populations. Marsden and Haag's (2016) empirical study of the development and use of personas by experts concluded that "person perception can bias design when working with personas, thus making it obvious how many difficulties the unreflected use of the persona method involves" (p. 4025). However, their HCI expert interviewees did not discuss bias, stereotypic attributions or the implications for design, leading them to conclude that, in general, these expert designers did not recognise "the responsibility to actively take ownership of the impressions generated by the personas" (p. 4026).

These last observations link to another key criticism: the commercial and political contexts in which personas are used. Rönkkö et al. (2004) found the impact of their personas was far outweighed by issues relating to the desire to use new technology and concerns about competition and market position. Massanari (2010) describes personas as "political tools that may oversimplify important differences between individuals using technological artifacts" (p. 407) within design organizations, serving to impose particular solutions: they "can be invoked to reduce conflict or win certain political disputes within the design team" (p. 411).

We acknowledge that the problems of stereotyping and political use of personas are significant. In the following, we suggest a modification to traditional approaches to persona construction that may help ameliorate these problems, particularly in contexts where the technology being designed is not a commercial product intended to generate economic return in a competitive market. While our approach does not address the non-falsifiability problem (Chapman and Milham 2006) - indeed, in attempting to create engaging and agentic personas we have embraced fictional narrative techniques - it may also provide a clearer relationship between personas and the user populations they represent through the explicit aims and processes of phenomenographic analysis.

\section{RE-THINKING PERSONA CREATION: VALUES NOT NEEDS}

We believe that some of the criticisms of personas outlined above may result from a widespread tendency to take users' perceived needs as the starting point for persona creation. In the following, we describe two research and design projects in which we came to the realisation that values (social, political and ethical) were more important than needs. One of these projects is funded through the European Commission's Collective Awareness Platforms for Social and Sustainable Innovation initiative, and the second was funded through the YOUNG-5b-2014 programme. Both projects are part of the broader Horizon 2020 programme.

Both projects were committed from the outset to using design personas (and scenarios) to inform the design of platform functionalities and interface features, anticipating basing them on needs and goals. It was only during the field research with potential users that the centrality of values and capacities emerged; our use of the methods of phenomenography (Marton 1986; Åkerlind 2012) turned out to be a powerful way of drawing out and maintaining this focus. Values and capacities subsequently became both the starting point and key emphasis in the creation of the personas: it is this that distinguishes our approach from others.

\section{PHENOMENOGRAPHY: AN ANALYTICAL APPROACH TO INFORM PERSONA CREATION IN HCI}

As described above, one of the criticisms levelled at persona use is the tendency towards stereotyping that seems inevitable when a large amount of qualitative data originating from different individuals is collapsed into a small number of personas. Given the already precarious and potentially marginalized nature of our target user groups (see below) and the emphasis on 
inclusivity and user participation at the heart of both projects, it was important to both avoid such stereotyping and ensure that the personas and scenarios represented not only the commonalities across, but also the range and richness of, the experiences. For this reason, the interviews were analysed using an approach developed from the methods of phenomenography (Åkerlind 2012; Marton 1981; Marton 1986).

Phenomenography was originally developed in the field of education studies, but has subsequently been applied in many other areas that make use of qualitative social science methods For example, phenomenographic analyses have been used in nursing and health research (Barnard, McCosker and Gerber 1999; McCosker et al. 2003; Sjöstrom and Dahlgren 2002); research into domestic violence (McCosker et al. 2003); studies of organisational change (Dunkin 2000) and business studies (Lamb, Sandberg and Liesch 2011). They have also been used in information research (Yates, Partridge and Bruce 2012) and sustainable design (Mann, Dall'Alba and Radcliffe 2007). In what follows, we extend the application of phenomenography to HCI and the creation of personas, especially when these may need to represent understandings, experiences, values and aspirations rather than just needs or problems and solutions.

Phenomenography is not a research method but rather an approach to the analysis of qualitative data that may have been collected in a variety of ways but most commonly through semi-structured interviews. It has much in common with Grounded Theory (Strauss and Corbin 1990), an approach to qualitative data analysis that is already in use in the HCI community (see Muller (2014) for an overview), but differs in some fundamental aspects. Grounded Theory looks to build theories of causal relationships. In contrast, phenomenography seeks to describe the range of ways in which people can experience the same phenomenon, and, in particular, to identify the qualitatively different components or dimensions that are responsible for that range. Phenomenographic researchers may also ask why two different people understand or experience the same phenomenon in different ways, but they do not attempt to construct causal theories. Instead, the focus is on the range of possible ways a particular phenomenon can be experienced: this focus on internal variation makes it "fundamentally different to other approaches" (Trigwell 2006, p. 370). It is this focus that makes phenomenography a potentially productive approach to building personas representing possible users, as it surfaces and supports the rich description of variations and different possibilities in users' experiences. It seems particularly well-suited for our research into different experiences of social and economic precarity (Commonfare) and young people's relation to environmental policy making (STEP), as we attempt to understand a multiplicity of experiences and perspectives, rather than collapse them into an average, and subsequently illustrate key aspects of this multiplicity to technical designers.

The object of study of phenomenography is the "variation in ... awareness or ways of experiencing a particular phenomenon" (Åkerlind 2012, p. 116). The aim of phenomenography is to develop a set of descriptive categories that illustrate similarities and differences in how a particular phenomenon is or can be conceived of or experienced. It has been described as "a research orientation" (Svensson 1997, p. 159) and "a set of assumptions about ... how we can acquire knowledge about other people's ways of experiencing the world" (Sjöstrom and Dahlgren 2002, p. 389).

Phenomenography is a non-dualist approach which does not recognize a division between an external, 'real' world, and internal, subjective representations of it: instead, one of its core ideas is that our experiences and understandings are constituted as internal relations. It also approaches human experience from a collective, rather than individualistic, point of view. 
This offers a further interesting element for $\mathrm{HCI}$ and the creation of personas, in particular for digital platforms where users are expected to conduct participative and collective activities by working together to achieve common goals, such as peer-production or participatory policymaking. Phenomenographic analysis views collections of interview transcripts or similar data as a set or whole, that gives access to different dimensions of experience. Within each dimension, there is variation in the way that dimension can be experienced, but these variations are not ascribed as the properties or characteristics of individuals but rather as of the set (or sample) as

a whole. Because of this, phenomenography provides a way of looking at experience of particular phenomena holistically, despite the fact that the same phenomena may be perceived differently by different people and under different circumstances.

As emphasised by Åkerlind (2012), phenomenographic researchers may approach data analysis in different ways, but there are some commonly shared elements of the process. The analysis is conducted through an iterative and comparative process of reading, discussing, and re-reading transcripts. Two or more researchers independently read each transcript in full, rereading often enough to familiarise themselves with the data. Preliminary categories relating to the way a particular phenomenon is experienced are then discussed and agreed on. Subsequent readings of transcripts look for sections that help clarify and refine those categories; this process is repeated until a stable set of categories is reached. The focus then turns to how variation within those categories can be described. The outcomes of the analysis represent "the full range of possible ways of experiencing the phenomenon in question, at this particular point in time, for the population represented by the sample group collectively" (Åkerlind 2012, p. 116). That is, we do not try to describe an average experience, but rather focus on difference and possibility.

The findings from the qualitative research in each of our projects are therefore set out as a series of dimensions of experience, within each of which one can find qualitative variation. In phenomenographic research, these dimensions and variations are referred to as an "outcome space" (Åkerlind 2012, p. 116) and are usually presented in tabular or matrix form with one axis representing dimensions of experience and the other qualitative variation within them. We adopt this representational convention in the following, and illustrate our outcome spaces in Tables 1 and 2.

\section{CASE STUDY 1: DESIGN PERSONAS FOR COMMONFARE.NET}

Commonfare.net (https://commonfare.net/) is a digital space that is being designed to facilitate a self-organising, bottom-up approach to social welfare, named commonfare (Fumagalli and Lucarelli 2015), as a means of countering the failures of State-based welfare in addressing the needs of the European population currently experiencing or at risk of experiencing poverty, precarity, and/or social exclusion. The commonfare approach is not intended as a replacement for State-based welfare (and therefore as a way for governments to reduce welfare responsibilities), but is, instead, an attempt to generate additional means of support and care. It has three core components: proper management (and reappropriation) of the commons; the distribution of an unconditional, universal, basic income; and development of complementary monetary or financial circuits (Fumagalli and Lucarelli 2015). It relies on the development and spread of grassroots, community-based initiatives intended to provide mutual help and support, and promotes a genuine sharing economy and recognition of the value of all types of human labour. The project is thus inherently normative, placing high value on social inclusion, cooperation, sharing, and mutuality. It is well-established (Chiu, Hsu \& Wang 2006) that shared values are important to the successful creation of (online) cooperative communities, and our platform design therefore consciously includes these values. As we shall see below, however, 
other values emerged as equally (if not more) important to potential users in the pilot research.

The personas described in this article were developed to inform two specific aspects of the commonfare.net design: the creation of a complementary monetary circuit in the form of a digital currency, and the inclusion of a reputation system to facilitate the creation of trusting relationships and interactions.

The commonfare.net project is a participatory design project involving academic, technical, and social activist partners working in collaboration with potential platform users drawn from communities in Croatia, Italy, and the Netherlands. Because the aim of the project is to improve the situations of people currently on the margins of European society, these potential platform users are drawn from specific target groups with whom local activist organisations already work. These are: in Croatia, young unemployed and precariously employed people; in Italy, unemployed and precarious workers; and in the Netherlands, precarious free-lancers, benefit recipients and non-Western migrants.

To inform persona creation, semi-structured interviews were conducted with 31 people (6 in Croatia, 12 in Italy and 13 in the Netherlands). Interviews explored interviewees' experiences of financial, employment, and social precarity and also aspects of their experiences of trust, distrust, and relationship formation. In the following, excerpts from these interviews are labelled with a country indicator (HR=Croatia, IT=Italy, NL=Netherlands) and an interviewee number.

The interviews were transcribed, translated where necessary, and read by the authors several times. They were treated as a set or pool of experience from which common themes could be identified, and within which variation could be found. Key themes and categories relating to the experience of financial and social precarity were identified, discussed among the authors and refined during the iterative process described above, with two authors initially analysing interview transcripts independently, then combining their analyses and verifying with the remaining authors. There was also some member checking through the distribution of a report to the design participants, who confirmed that they felt the reported findings mirrored their experiences.

\section{Phenomenographic analysis for commonfare.net design persona research}

Because the contexts of the different target groups are in some ways quite different, some practical differences quickly emerged. For example, unique to the Croatian context was the common experience of reliance on parents for accommodation and food, in the face of being unemployed and receiving no state support; and unique to the Italian context was the experience of being paid in vouchers rather than currency. However, there were also important commonalities across the pilots, and differences within each pilot.

The main dimensions of experience we found from our interviews were:

- Values and aspirations

- Relationships with

$\circ$ the State/system

- family/friends

- nature/the environment

- Practical problems/daily life

- Time

An important source of variation within these dimensions stemmed from how much freedom for movement, dignity, and control interviewees felt they had over their own lives. 
While all interviewees were or had been experiencing financial precariousness, some were in this position as a result of what they felt to be their own life choices, whereas others felt it to be forced on them by circumstances beyond their control. People also experienced different levels of agency with respect to what they could do to change their situation (if they wanted to). This difference meant that each of the dimensions was experienced in different ways, depending on the degree to which interviewees felt (at that moment, or in that context) in control. This variation in degree of perceived autonomy or empowerment provided the logical, structural relationships within the dimensions of experience that are essential to phenomenographic analysis. Here, we illustrate our findings in more detail in relation to the dimensions of experience 'Values and Aspirations' and 'Relationships with the State,' in order to show how they influenced the resulting personas.

Evidence for the criticality of dignity and autonomy as values to be respected in the design process

Although we did not explicitly ask interviewees about their values, their answers to various questions and their descriptions of their experiences suggested that, for many, maintaining a sense of their own freedom, independence, and dignity was important:

I am very proud of my family, as we have always lived with dignity. (IT7)

I always keep a standard where I feel good. (NL7)

It's also more freedom, being free to get out, not owning a place ... (HR2)

... I don't want to get caught back in that trap, the trap of the social system. (NL13)

An aspect of their experiences that emerged as important in creating or diminishing interviewees' sense of agency and self-authorship was whether they saw themselves as following a vocation or (social) mission. Related to this was the question of where interviewees identified the source of their own value or self-worth, in relation to talent, work, and/or contribution to society.

A sense of control over one's own existence was often accompanied by evident pride in a talent being put to good use or the decision to follow a vocation rather than prioritize stable income:

$$
\begin{aligned}
& \text { [I'm] proud to have had the courage to listen to the heart and stop a job, losing } \\
& € 3000 \text { per month, to stay happy ... it was a very difficult decision because I had } \\
& \text { nothing, but I managed it, and it ended up being a statement. The reactions were } \\
& \text { very interesting, some of the other dancers in the company were shocked. They } \\
& \text { would like to do it but didn't know how ... it was a decision of path. (NL7) }
\end{aligned}
$$

This notion of "path" was important to many of those interviewees who expressed a sense of control over their lives. It was often coupled with a belief that the interviewee was contributing to society in some way, either through the work they were doing or through socio-political activism. This contribution might be at the level of helping individual people, contributing to reform within a profession, or attempting to remake society at large.

There was a related theme of to what extent, and in what ways, interviewees felt their own value to be determined by work. Here, again, the extent to which interviewees felt themselves to be in control was important. For some, the determination of their value through work was seen as culturally imposed. For others, this cultural norm had been internalised, and produced intense frustration when opportunities to demonstrate value through work were not 
available.

For others, "path" and necessity were in tension. While able to see that precariousness might offer some freedom, some interviewees described how the reality of the situation meant they were not really free to do anything other than work. For example, one Italian precarious worker described how his "passion is writing poetry and also prose," but then went on to tell us that "you are so much projected into the need to work, it is hard to feel realized and satisfied as you cannot do those things you would like to do" (IT5).

The dimension of experience 'Relations with the State' also illustrates the high value users placed on freedom and dignity, most often by referring to their erosion. Interviewees described "corrosive" and "embarrassing" interactions with the State using terms such as "chains" and "slavery." This not only reinforced people's desires for freedom and independence, but also gave rise to a generally high level of political awareness and distrust. Almost every interviewee expressed generalised distrust of and disaffection from the political and business systems. The attitude among young Croatians can be summarised by the statement, "Of course it's only logical that I don't trust the State" (HR1).

Many of the interviewees showed a keen awareness of politics and the social impact of both government policies and capitalist economics. Many interviewees in Italy and the Netherlands expressed anti-austerity or anti-capitalist views, and all Croatian interviewees made disparaging comments about their own government. One Dutch interviewee described how a right-wing city government "made several measures that stimulate poverty instead of repairing it" (NL3).

A final recurrent theme reflecting interviewees' relationships with the State and society as a whole relates to the representation of unemployed and precarious people in the media and the attitude society holds towards them. Interviewees in all three countries described a pervasive culture in which the poor and precarious were seen as at fault for their condition, in what was widely referred to as a "blame the victim" (NL5) culture.

Phenomenographic outcome space for commonfare.net currency and reputation system persona research

The final set of dimensions of experience and variation within them relating to sense of agency we found in our analysis are presented in Table 1 . These dimensions and variations formed the basis for creating the personas and scenarios needed to inform the design of the reputation system, digital currency, and network dynamics elements of commonfare.net. 
Table 1: Phenomenographic outcome space for the experience of employment, financial, and social precarity of interviewees in the commonfare.net project.

\begin{tabular}{|c|c|c|}
\hline $\begin{array}{l}\text { Dimension of } \\
\text { experience }\end{array}$ & $\begin{array}{l}\text { Low sense of agency/self- } \\
\text { authorship/control }\end{array}$ & $\begin{array}{l}\text { High sense of agency/self- } \\
\text { authorship/control }\end{array}$ \\
\hline $\begin{array}{l}\text { Values and } \\
\text { aspirations }\end{array}$ & $\begin{array}{l}\text { - Loss of freedom and dignity } \\
\text { - Feeling one's value to society lies } \\
\text { in capacity to contribute } \\
\text { professionally, but no opportunity } \\
\text { to do so } \\
\text { - Aspirations tempered by realism, } \\
\text { or feeling unable to think of the } \\
\text { future }\end{array}$ & $\begin{array}{l}\text { - Maintaining a sense of freedom } \\
\text { and dignity } \\
\text { - Pursuit of a vocation and/or } \\
\text { social mission gives one's } \\
\text { actions value } \\
\text { - Self-improvement in pursuit of } \\
\text { own goals }\end{array}$ \\
\hline Relationships & $\begin{array}{l}\text { - Erosion of freedom and dignity in } \\
\text { interactions with State } \\
\text { - Complete loss of trust } \\
\text { - Looked down on by others, blame } \\
\text { the victim } \\
\text { - Isolation from supportive } \\
\text { networks of friends/family } \\
\text { - Inability to settle down, start a } \\
\text { family }\end{array}$ & $\begin{array}{l}\text { Two-way flows of social } \\
\text { capital, i.e. individual offers as } \\
\text { well as receives support } \\
\text { - No need for trust in the State if } \\
\text { interactions with it can be } \\
\text { avoided } \\
\text { - Feeling able to form settled } \\
\text { intimate relationships, start a } \\
\text { family if desired }\end{array}$ \\
\hline $\begin{array}{l}\text { Practical } \\
\text { problems }\end{array}$ & $\begin{array}{l}\text { - Inability to cope without help } \\
\text { - Debt and indebtedness }\end{array}$ & $\begin{array}{l}\text { Pursuit of a vocation and/or } \\
\text { social mission makes it worth } \\
\text { putting up with material } \\
\text { deprivation } \\
\text { - Cooperative strategies such as } \\
\text { food-buying groups, } \\
\text { occupations }\end{array}$ \\
\hline Time & $\begin{array}{l}\text { - } \quad \text { Time poverty } \\
\text { - } \quad \text { Time slipping away }\end{array}$ & $\begin{array}{l}\text { - Able to use time wisely } \\
\text { - Investing time in self- } \\
\text { development }\end{array}$ \\
\hline
\end{tabular}

\section{Creating personas for commonfare.net}

Our analysis of the interviews suggested it was essential to construct design personas and scenarios that reflected the high value placed on dignity and autonomy by the people we had talked to. The interviews also offered rich illustrations of the emotional states, aspirations, goals, and frustrations of our interviewees, including in relation to their interactions with the State and other controlling factors. We therefore set out to create personas and associated scenarios that explicitly included (and even made central) such feelings and experiences.

In total, we constructed six design personas and, ultimately, nine related scenarios. Here we discuss only personas (further discussion of the commonfare.net scenarios can be found in Sciannanamblo et al. (2018)). The personas took the form of combined text and photographic image elements, including a name, demographic information and the following sections: 
- Financial situation

- Educational history

- Work history/skills

- Home circumstances

- Internet use

- Emotional state/personality traits

- Goals

- Frustrations

- Quotes

Figure 1 is an example of a complete persona created for the commonfare.net digital currency and reputation system features. As is evident from this example, these personas were (deliberately) rather reliant on text-based narrative, written to create pictures of believable and engaging characters. Here, however, we focus on the way the personas foreground the dimensions of experience and variation in relation to agency described above.

The first three text sections in the personas consisted mostly of 'factual' (although fictional) information that would be typically included in a design persona. The remaining categories were deliberately scripted to focus more on the social, political, and ethical values that had emerged during the analysis. The language used in the text of the personas included phrases indicating what is or is not valued, for example:

- Valuing being in work as a source of self-worth, e.g.: "is unhappy, but feels that any job is better than none"

- Valuing stability in housing, e.g.: "glad to own [their home] for themselves"

- Beliefs about what is fair and just, e.g.: "does not like ... avoids ... is irritated by .... Believes that it is unfair"

- Ambivalence or distrust of the internet and social media, e.g.: "worries about using the internet too much," "worried about the impact of social media use on her children."

The personas were carefully constructed to reflect not only the dimensions of experience, but also the variations within them and the key role of a sense of agency and control in that variation. We endeavoured to create a set of personas that included people currently experiencing a strong sense of agency and control over their lives, others whose current situation left them feeling precarious in terms of control as well as in relation to work and money, and others still who felt strong control over some aspects of their life but less over others, such as difficulties interacting with the State. For example, we included phrases such as "sense of uncertainty and doubt" ... "feels constant pressure" ... "suffering from loss of selfesteem" to convey a diminished sense of agency. However, such phrases could also figure in descriptions of characters who had a strong sense of self-authorship. For example in the persona shown in Figure 1, Ana is described as having deliberately decided to avoid reliance on State aid because when she applied, she "felt [the process] was soul-destroying."

The apparent importance of both positive and negative relationships revealed by the interviews also suggested that individualized discourses of success and failure are inadequate; this needed to be reflected in the personas and scenarios we developed. Thus, the scenarios in particular highlighted dependencies, contingencies, and cooperation - sometimes connecting personas across scenarios, sometimes using chance meetings or interactions to prompt the beginnings of longer term change. 


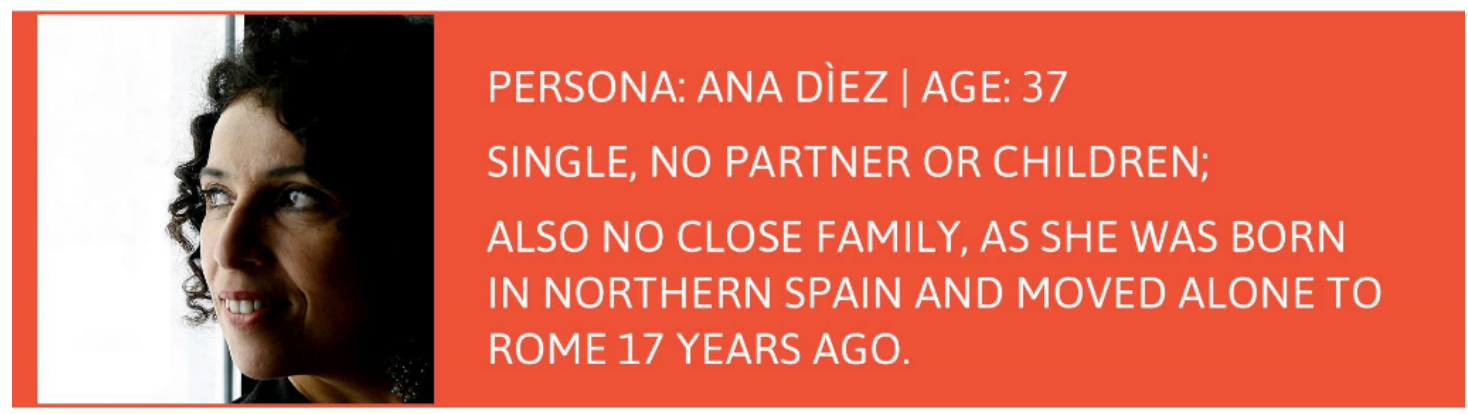

\section{FINANCIAL SITUATION}

Ana is a freelance web designer. She has sufficient income to cover her daily expenses and she always makes sure that she has at least three months' worth of savings. Right now she has enough to live on for about 6 months. She has no pension.

\section{EDUCATIONAL HISTORY}

Ana has a degree in Fine Art. She has taught herself to use various web design packages. She is continually engaged in selfstudy, especially around her passion, which is to make creativity and art part of everyone's lives, particularly those who might usually be cut off from it through disability or illness.

\section{WORK HISTORY / SKILLS}

After graduating, Ana got a job in a private art gallery. This work brought her into contact with wealthy people who were buying art purely as status symbols, with no real eye for talent or understanding of the political dimension of engaged art. Ana felt it was soul-destroying, and decided to quit in 2005 .

Ana then worked in various short-term and cash-in-hand jobs in cafes and bars. While doing this, she settled on the idea of freelance work in the area of web design. This work allows her to make use of her artistic talents while also allowing her to choose what kinds of people and organizations she creates sites for. Equally importantly, she can work when she likes, often doing so in the evenings and into the small hours. Ana works enough to get by but does not want all her time to be taken up working. She is not motivated by money. It is more important to her to have time to use her skills and talents to help others. She does this by providing arts based therapy to autistic/disabled young people through activities she runs at community health centres in her city.

\section{HOME CIRCUMSTANCES}

Ana rents a small apartment in Rome. She is a vegan and environmentalist, and prefers to eat organic produce. She keeps her flat spotlessly clean; although it is rather sparsely furnished, a few treasured objects (small hand-made sculptures, pieces of driftwood, old photos of her family back in Spain) give it a personal and welcoming feel. Ana has a small, close-knit group of friends, mostly met through artistic and activist activities, and many of them (like her) are migrants to Italy. However, despite these close friendships, Ana is fiercely independent and prefers to stay single.

\section{INTERNET USE}

Ana uses the internet daily for work, mostly on her laptop. She is not registered on any freelancer sites and instead has her own website, which includes links to examples of her work and some testaments from former clients. She does not use a survey to gather feedback from her clients, feeling that if they want to say something to her they will.

Ana also uses the internet for self-education, for example keeping up to date with the latest ideas and developments in arts-based therapy provision. She is on Facebook, but only uses it to find out about cultural and activist events, or to find organizations that might be interested in partnering with her to promote or provide space for her arts-based therapeutic workshops. She worries about using the internet for too much, however, and is concerned that it is both addictive and toxic. She prefers her friendships to develop in the physical world.

Emotional state/personality traits

Independent, self-sufficient, proud, calm, and generally happy with her life.

\section{GOALS}

Staying independent / Helping others by engaging them in artistic and creative activities / She knows she should start thinking about saving for the long term soon

\section{FRUSTRATIONS}

Sees modern society as too materialistic and selfish / Dislikes wastefulness

\section{QUOTES}

"It's my life and I'm in control of it. I can always find stability in all this instability."

"I think what would appeal to me is to have a sense of community with people who are all trying to make ends meet in ways that are different from what is conventional at the moment. And to see how they do it and maybe help each other out."

"Without trust there is no ability to move forward, to make a connection ... I believe respect is a good starting point to have trust. But the relationship and trust and respect are built together"

Figure 1: An example of a completed Design Persona for commonfare.net. 
Our desire to convey values and beliefs rather than simply needs was also a strong motivation for the inclusion of the section "emotional state/personality traits," and for closely associating this with the goals and frustrations sections by means of the visual layout of the personas. Thus in the persona in Figure 1, the description of Ana as "independent, self-sufficient, proud, calm and generally happy with her life" deliberately avoids ascribing needs to her that the platform could satisfy. In addition, the inclusion of both "staying independent" and "helping others by engaging them in artistic and creative activities" immediately after this charactersketch places emphasis on the need for designers of commonfare.net to think about how the platform might create opportunities for her to exercise her capacities for independence and contributing to the well-being of others. This is in marked contrast with a needs-based approach, which might have led to a persona focused on Ana's need to get information on pensions or get more freelance work. Thus by taking values and capacities as our starting points, we created personas that themselves had dignity and socio-political agency.

\section{CASE STUDY 2: DESIGN PERSONAS FOR STEP}

We now turn to our second example from the STEP project, an EU Horizon2020 project (www.step4youth.eu ), completed in December 2017, that developed and piloted a cloud based eParticipation platform (https://en.step.green/) in five municipalities and regions in Italy, Spain, Turkey, and Greece. The goals of STEP were: 1) to enable policy makers to open up their environmental decision processes to a wider audience and 2) to enable young people, who were the main target group for the project, to actively participate in the shaping of policies. The project's success depended on capturing the multiplicity of users' perspectives, in order to create a digital platform solution supporting users' active participation. Our goals were twofold:

- $\quad$ To understand what policy makers perceived they would need to enable them to open up their decision making and what obstacles they saw for young people's participation; and

- To understand young people's perspectives on what would make the platform relevant to their life and what would encourage them to express their opinion and potentially take action.

As in the Commonfare.net project, STEP developed personas and scenarios based on empirical research. We shall discuss here only the personas, focusing on young people.

One important concept that has underpinned the project is that of facilitating agency and capacity with respect to the environment. Having a positive attitude towards the environment does not necessarily translate into the desire of young people to take action for positive change. Whether or not action is taken depends on values which may include global issues such as younger people having more at stake in the future of the planet than older people, and local values such as improving and helping out their own local community. However, within STEP, these motives need to be translated into the capacity of young people to participate in decision-making on policies. It is widely accepted that there is a gap between a positive environmental attitude and participating in concrete action for the environment (see, for example, European Commission 2008). Research has also pointed to a decline in public participation and social capital (Putnam 2001) at a general level, which also impinges on participation regarding environmental action. The goal of STEP was to bridge the gap between intentions and action by engaging young people in shaping policy and participating in decision making, and thus to partially counteract this decline.

Many of the factors that influence positive environmental attitudes (Dietz et al. 1998), such as age, social class, residence (urban/rural), political orientation, sex/gender, social/cultural norms, and socialization processes cannot be changed through the design of a 
platform for eParticipation; they have to be acknowledged as pre-existing, external conditions. The STEP project therefore adopted a strategic focus on the idea of environmental action. This does not require attempts to change long-term demographic factors or social processes, but instead affords a focus on the situation in which young people currently find themselves. Social action requires intentionality and can be directed towards instrumental goals but also towards values (see, e.g. Weber 1978). In this regard, environmental action has been defined as "a deliberate strategy that involves decisions, planning, implementation, and reflection by an individual or group ... intended to achieve a specific positive environmental outcome" (Emmons 1997, p. 35). Thus, the problem for building personas for STEP became one of capturing aspects of young people's capacity to take action.

To develop personas we interviewed 28 young people (14 females and 14 males) between 18 and 29 years of age representing 9 different EU nationalities (5 living in European countries different from their nationality). Seven interviews were conducted in the national language in order not to exclude young people who do not speak English. Interviews were organized in two parts: a main/general part aimed at gathering background knowledge around the social context in which users live and work, and a specific part with questions directly related with the engagement with environmental issues and desires of technological support for achieving their goals in this area. Our intention was to uncover users' value propositions through exploring users' understandings of what the STEP platform was for, what opportunities it offered, and how users' currently understood and experienced issues relating to the environment and social action.

\section{Phenomenographic analysis for STEP persona research}

Applying phenomenographic approaches to the analysis of the interviews undertaken for the STEP project meant, as with commonfare.net, treating interviews as a pool of understandings and looking within that pool to find the qualitatively different dimensions that defined those understandings and the variation in ways the dimensions were experienced. The interviews were transcribed in full but then analysed together, avoiding assigning individual respondents to categories of experience and instead looking for common issues or experiences that might, however, be experienced in very different ways or viewed from different perspectives.

The main dimensions associated with taking action or the obstacles for action we found were:

- Young people's attitudes to and beliefs about policy makers

- Perceptions of the quality, availability, and relevance of information about the environment

- Perceptions of the scope of responsibility

A key source of variation in the dimensions of experience was trust. Another key source of variation, similarly to our findings in the commonfare.net research, was young people's sense of agency and control. In some cases, this was at the level of the individual - such as when young people felt they could have no impact because their voice would not be listened to. In other cases, however, the young people interviewed for STEP experienced agency (or a lack of it) on a wider scale, for example when considering the impact of the potential actions of a relatively small country. It seemed, from our interviews, that variation in trust and sense of agency were key factors in determining whether young people would take action: this led to a realization that the STEP platform might best enable such translation by maximizing opportunities for engagement and action at the local level, where sense of agency appeared to be strongest. 
Evidence for the criticality of values around trust and local action in the design process

Trust, or the absence of it, seemed to be a critical issue for interactions between young people and policy makers and for their expectations of each others' behaviour. Expressions of mistrust were more common than of trust, particularly among the young people we interviewed. Many of these young people had a generalized mistrust of policy makers, in particular politicians, assuming them to be more likely to act out of self-interest than for the general good. Some young people believed that policy makers were likely to engage in eParticipation activities to enhance their profile and popularity in order to win votes, rather than because they saw genuine value in involving young people in decision-making processes, as illustrated by the following two excerpts:

\section{An obstacle is that politicians don't give us much of their time, they are thinking of their own opportunity not about Young People. (Italian YP) \\ People might participate just for the image, I think some politicians would do this. (UKYP)}

Lack of trust could also arise from perceptions of cultural barriers between young people and policy makers, as the following excerpt indicates:

Policy makers think that it is difficult to have a relationship with the citizens. I think they need to go to the square more and speak to the people, and publicise things more using the internet. Not only for issues on the environment but for other policies. (Italian YP)

Against this background of low expectation of trustworthiness, policy makers could make things even worse through their actions in relation to environmental policy, or indeed their lack of action, so that they could contribute into turning a generalized mistrust into a more evidencebased and therefore active distrust.

However, some young people indicated that an eParticipation process could be an opportunity for a significant increase in the transparency of decision-making processes and consequently an increase in the potential to trust policy makers and their actions:

Facilitating discussion between policy makers and citizens - for me it would be quite interesting if we could get space to see the background of the decision making. What are the advantages and disadvantages of the policy? Usually we cannot see the background at all - we cannot understand the reason for the decision and it can be frustrating. (Hungarian YP)

The sense of agency of young people in relation to environmental issues and policy-making was clearly related to their degree of trust in policy makers - if you do not feel your voice will be listened to, you will not trust someone to act in your interest. This is clearly captured in the following excerpt:

I am not convinced that the politicians will care about the opinions. (Hungarian YP)

However, a second major factor in young people's experiences of agency was perceptions of the potential impact of actions at the individual, local, and global level. This, in part, reflected varying values placed on local and global issues. Many of our interviewees expressed an awareness that we all live on the same planet and that what happens in other countries often has a direct effect on everyone else. They were also more pessimistic over the long-term global outlook. They felt that positive environmental actions could make a difference at a local level, 
however they felt more powerless to address global issues such as climate change. Thus a focus on participatory local policy-making would have had better chances to translate into young people action than focusing on global issues.

However some interviewees believed that small, local actions could have some global impact:

Global is more important, but the way to achieve this is through local action and local groups. If everyone works together and takes it bit by bit, rather than starting for a massive global scale then we might be able to do it. If everyone did a little bit then it would help. I think it's needed to have this global impact. (UK YP)

These excerpts illustrate how variation in sense of agency, including a distributed agency at the level of local communities, impacts on how likely it is for individual young people to translate attitudes to the environment into concrete action. They also show how important trust in policy makers and politicians is in deciding whether the action of participating in decision-making processes is worthwhile.

Table 2: Phenomenographic outcome space for young people's likely participation in action towards the environment emerging from the STEP project

\begin{tabular}{|c|c|c|}
\hline $\begin{array}{l}\text { Dimension of } \\
\text { experience }\end{array}$ & $\begin{array}{l}\text { Low sense of trust/low sense } \\
\text { of agency }\end{array}$ & $\begin{array}{l}\text { High sense of trust/high } \\
\text { sense of agency }\end{array}$ \\
\hline $\begin{array}{l}\text { Attitudes to and beliefs } \\
\text { about policy makers } \\
\text { and politicians }\end{array}$ & $\begin{array}{l}\text { Mistrust towards policy } \\
\text { makers } \\
\text { - Perceptions of large cultural } \\
\text { barriers between young } \\
\text { people and policy makers } \\
\text { - Assumption that policy } \\
\text { makers act for their own } \\
\text { benefit rather than the } \\
\text { public interest } \\
\text { - Sense of potential } \\
\text { exploitation }\end{array}$ & $\begin{array}{l}\text { Placing trust towards } \\
\text { environmental NGOs and } \\
\text { other non-governmental } \\
\text { actors } \\
\text { - Willing to give policy } \\
\text { makers an opportunity }\end{array}$ \\
\hline $\begin{array}{l}\text { Quality and relevance } \\
\text { of information }\end{array}$ & $\begin{array}{l}\text { - No clarity about quality of } \\
\text { information produced by } \\
\text { user communities } \\
\text { - Perception that some } \\
\text { necessary information is } \\
\text { hidden }\end{array}$ & $\begin{array}{l}\text { - Perceives opportunity to } \\
\text { raise awareness of projects } \\
\text { going on in the area } \\
\text { - Perceives opportunity to } \\
\text { have informed discussion } \\
\text { about policies } \\
\text { - Feels that information can } \\
\text { be tailored to young people }\end{array}$ \\
\hline Scope of responsibility & $\begin{array}{l}\text { - Global problems like climate } \\
\text { change difficult to tackle }\end{array}$ & $\begin{array}{l}\text { - Concentrating on local } \\
\text { environmental problem can } \\
\text { produce visible effects }\end{array}$ \\
\hline
\end{tabular}


Phenomenographic outcome space for STEP persona research

Table 2 on the preceding page presents the outcome space describing the dimensions of experience we found in the interviews. It highlights the variation within the dimensions depending on trust and agency.

\section{Creating personas for STEP}

Our personas have been designed to embed the values emerging in the phenomenographic analysis described above relating to creating high senses of trust and agency. These were then used to inform the design of the platform's core features and user interface.

In total, we constructed eight personas (six young people and two policy makers). The personas took the form of combined text and photographic image elements, including a name, demographic information and the following sections:

- General Environmental Attitude for Action (not labelled as such in the persona itself, and forming the main text block)

- Goals

- Motivations

- Frustrations

- Quotes

- Behaviour (in the form of visual indicators of levels of environmental concern, involvement in civic life and social media use)

Figure 2 shows an example of a complete persona from the STEP project.

As with the personas for commonfare.net, the language used in creating the personas was critical to conveying the values and beliefs of the interviewees that related to their likely participation in local policy-making processes through the STEP platform. Words and phrases were chosen to show not only the dimensions of experience but also variation within them. Examples showing variations in trust and agency included:

- In relation to attitudes to policy-makers and politicians and likely engagement with them: "feels that her voice is not heard and that politicians are only interested in themselves," "not that interested in politics," "thinks the political system is 'a mess'," "enjoys debating issues," "thinks it is very important to be politically engaged."

- In relation to perceived responsibility: "not hugely concerned about the environment," "believes that most environmental actions are just delaying the inevitable demise of the planet," "very interested in policies that directly affect them and their families," "keen for her workplace to become greener and adopt more sustainable policies," "likes to find and share upcycling ideas," "thinks that threats to the environment are greater and stronger than ever ... believes in locally produced food which has a much lower carbon footprint," "concerned about the relationship between developed and underdeveloped countries."

Again, these personas were deliberately constructed to avoid presenting potential users as individuals with problems that could be solved or needs that could be fulfilled through the STEP platform itself. Instead, they were developed to suggest how the platform could reflect users' values and beliefs, and include features that would let them exercise their own capacities. For example, the persona in Figure 2 emphasises local action; it suggest Jan's goals are to do with outreach, increasing engagement and change, rather than meeting immediate or personal needs. It describes frustrations with issues that STEP itself is unlikely to be able to resolve, such as information overload and the misconceptions of policy makers, but that should be taken into account in the platform's design. 


\section{(Jan Cerny)}

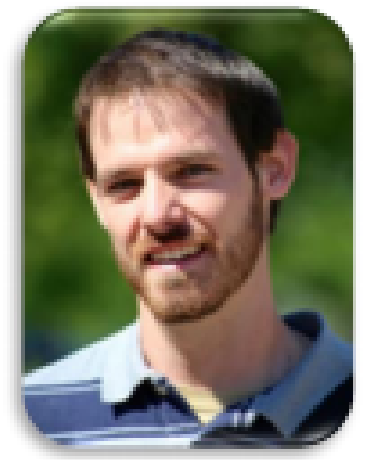

Jan works at a local environmental NGO. Graduated with a degree in Environmental Engineering from a University in Latvia. He is also involved in a local Youth Organisation, working as a group leader. He takes groups of young people to enjoy the outdoors and the local natural environment. He has recently moved to a flat with a roof garden is enjoying experimenting growing some vegetables and herbs organically. He doesn't buy a newspaper or own a TV but listens to music and the radio at home. He gets his news online and by following his interests on Twitter.

Jan does use Facebook and Twitter, he accesses them from a computer, he also uses the internet quite a bit. He uses Facebook to stay in touch with friends but is not an avid user. He also has to use it to inform the local youth group about upcoming activities. Jan was interested to see

Uves in: Prague

Age: 28 that local politicians seem to be using Twitter recently. Jan had previously used a Moodle (type of University Virtual Learning

Occupation: Works at a Environment) whilst he was studying to discuss environmental issues. local environmental NGO. The Moodle group was set up for the students but the discussion group was Public and you could discuss issues with other people from different countries. Discussions were mediated by a Webmaster who raised different issues. He enjoyed using the platform and would like to use the STEP platform to do this again. Jan recently got rid of his smartphone and bought an older type phone just to make calls, since he found the smartphone was too much of an intrusion and contributed to information overload. When he is outdoors- he doesn't want to be online all the time.

\section{Goals}

- To improve Environmental Education of Young People via outdoor activities.

- Increase the numbers of Young People participating in his local Youth Group

- Change the Government Policy on Small Hydroelectric Schemes

\section{Motivations}

- Enjoys spending time in the natural environment

- Enjoys sharing his love of nature with other young people

- Would like to contribute to protecting the local aquatic habitats by campaigning against the Hydro schemes

\section{Frustrations}

- Difficulty in getting Young People to commit to longerterm projects

- Hates Information overload and the intrusion of technology on everyday life.

- Policy makers thinking that renewable energy must always equate to green when it is sometimes damaging to the environment

\section{Quote}

"it's easy to engoge people for the fun things, harder to get them to commit longer term"

\section{Behaviour}

Environmental concern

Cvic life inwolvement

Social medla u se

Figure 2: Example persona from the STEP project 


\section{DISCUSSION AND CONCLUSIONS}

We suggest that careful analysis of users' beliefs and values, and construction of personas and scenarios using carefully chosen language, contextual, and narrative details to express these, can help to avoid the problem of stereotyping by retaining the tensions, contradictions, and value-conflicts that characterise real human experience. An emphasis on values and beliefs also makes the political dimension of personas explicit, allowing the politics of the users into the same space as those of the designers, engineers, funding organizations and so on.

The two case studies described above illustrate a process of persona creation that avoids presenting users as objectified consumers of a product or service to be offered by the platform being designed, with that product or service designed to satisfy (and simultaneously create) needs. Instead, the process is intended to result in personas that present people with values, beliefs, and associated desires whose self-authorship might be facilitated through the platforms, if they are designed to allow users' to exercise and, perhaps, develop their own capacities for action.

We believe that because of this, our personas may avoid, or at least reduce, some of the risks associated with using design personas described earlier in this paper. Goh et al. (2017) suggest that the use of personas to convey local cultural contexts has recently become significant; our approach goes beyond considering the average or typical impact of local cultural contexts to attempt to show variation across and within local contexts, particularly in terms of values and beliefs. Thus we do not produce, for example, Croatian personas that all experience their precarity as disempowering, but rather personas that experience different degrees of selfauthorship while experiencing similar external conditions. Our focus on variation as well as commonality, which has been facilitated through our use of phenomenographic approaches to qualitative data analysis applied to the creation of design personas, offers a way of reducing the tendency to stereotype (Turner and Turner 2011; Marsden and Haag 2015). It does this both by highlighting variation in the experiences and perceptions of the interviewees who contribute to the pool from which the personas are drawn, but also by shifting our focus from creating artificially self-consistent individuals (recognizing that internal tensions and conflicts are part of normal human experience), and allowing such tensions and conflicts into individual personas.

Our process also highlights the importance of including textual elements that emphasise users' capacities and desires more than their needs. That is, we include both explicit and implicit references to moral, social, and political beliefs and values, and connect these with common elements of design personas such as 'goals' and 'frustrations.' By making our personas carry political intentions and tensions, we thus hope to minimize the possibility of their being used in a political way within the design process, to advance the agendas of people other than the users (Massanari 2010). We hope that our process produces design personas that have some agency of their own.

Of course, our approach does not mean that we avoid all the potential problems associated with the use of personas and scenarios in the design process. We do not yet know how much impact they had on other designers involved in the projects, but within our own work they had a profound effect on how we viewed the creation of a reputation system for the Commonfare project in particular. We suggest that further research, perhaps through an ethnographic study of the use by technical designers of personas that deliberately emphasise values and capacity over needs, problems, and solutions, would be highly desirable in order to determine whether they do, indeed, reduce designers' perceptions of personas as abstract and impersonal. Also, while we believe that the story-telling function of personas and scenarios may 
be an important contributor to their effective impact on design, our approach remains open to criticism regarding scientific falsifiability (Chapman and Milham 2006).

In conclusion, we have described an approach to creating personas which moves away from needs, to emphasise more value-beliefs and capacity, and consequently personas actions (in scenarios) to achieve these beliefs via the designed technology. While there are likely to be approaches and research processes that can lead to similar results, we suggest that shifting the focus from needs to capacities, and from commonality and consistency to variation and tension, is an important step in creating personas for political and social consciousness in HCI design.

\section{ACKNOWLEDGEMENTS}

This paper has received funding from the European Union's Horizon 2020 research and innovation programme under grant agreements No 649493 and No 687922. The paper reflects only the author's view and the Research Executive Agency or European Commission is not responsible for any use that may be made of the information it contains.

\section{WORKS CITED}

Åkerlind, GS 2012, 'Variation and commonality in phenomenographic research methods', Higher Education Research \& Development, vol. 31, no. 1, pp. 115-127.

Anvari, F \& Tran, HMT 2013, 'Persona ontology for user centred design professionals', in J Bloomer, M Nkhoma \& N Leung (eds), Proceedings of the ICIME 4th International Conference on Information Management and Evaluation, Ho Chi Minh City, Vietnam, pp. 35-44.

Anvari, F, Richards, D, Hitchens, M, Babar, MA, Tran, HMT \& Busch, P 2017, 'An empirical investigation of the influence of persona with personality traits on conceptual design', Journal of Systems and Software, vol.134, pp. 324-339.

Avison D, \& Fitzgerald, G 2003, Information systems development: methodologies, techniques and tools, 3rd edition, McGraw Hill, Maidenhead, UK.

Barnard, A, McCosker, H \& Gerber, R 1999, 'Phenomenography: a qualitative research approach for exploring understanding in health care', Qualitative Health Research, vol. 9, no. 2, pp.212-226.

Carroll, JM 2000, Making use: scenario-based design of human-computer interactions, MIT Press, Cambridge MA.

Chapman, CN \& Milham, RP 2006, 'The personas' new clothes: methodological and practical arguments against a popular method', in Proceedings of the Human Factors and Ergonomics Society Annual Meeting, vol. 50, no. 5, pp. 634-636.

Chiu, CM, Hsu, MH \& Wang, ET 2006, 'Understanding knowledge sharing in virtual communities: An integration of social capital and social cognitive theories', Decision Support Systems, vol. 42, no. 3, pp. 1872-1888.

Cooper, A 2004, The inmates are running the asylum:[Why high-tech products drive us crazy and how to restore the sanity], SAMS, Indianapolis IN.

Cooper, A, Reimann, R \& Cronin, D 2007, About face 3: the essentials of interaction design, John Wiley and Sons, Indianapolis IN.

Dietz, T, Stern, PC \& Guagnano, GA 1998, 'Social structural and social psychological bases of environmental concern', Environment and Behavior, vol. 30, no. 4, pp. 450-471.

Dunkin, R 2000, 'Using phenomenography to study organisational change', in JA Bowden \& E Walsh (eds), Phenomenography, RMIT University press, Melbourne, pp. 137-152.

Emmons, KM 1997, 'Perspectives on environmental action: reflection and revision through practical experience', The Journal of Environmental Education, vol. 29, no. 1, pp. 34-44. 
European Commission 2008, 'Attitudes of European citizens towards the environment. Eurobarometer 295', retrieved 31 March 2018, http://ec.europa.eu/commfrontoffice/publicopinion/archives/ebs/ebs 295 en.pdf

Floyd , IR, Jones, MC \& Twidale MB 2008, 'Resolving incommensurable debates: a preliminary identification of persona kinds, attributes and characteristics', Artifact, vol. 2, no. 1, pp. 12-26.

Fumagalli, A \& Lucarelli, S 2015, 'Finance, austerity and commonfare', Theory, Culture \& Society, vol. 32, no. 7-8, pp.51-65.

Goh, CH, Kulathuramaiyer, N \& Zaman, T 2017, 'Riding Waves of Change: A Review of Personas Research Landscape Based on the Three Waves of HCI', in J Choudrie, MS Islam, F Wahid, JM Bass \& J Eka Priyatma (eds), 14th IFIP WG 9.4 International Conference on Social Implications of Computers in Developing Countries, Yogyakarta, Indonesia, pp. 605-616.

Gothelf, J \& Seiden, J 2013, LEAN UX - Applying LEAN principles to improve user experience, O’Reilly, London.

Gudjonsdottir, R 2010, 'Personas and scenarios in use', PhD Human-Computer Interaction thesis, KTH, Sweden, retrieved 22 October 2018, http://www.divaportal.org/smash/get/diva2:319155/FULLTEXT01.pdf

Lamb, P, Sandberg, J \& Liesch, PW 2011, 'Small firm internationalisation unveiled through phenomenography', Journal of International Business Studies, vol. 42, no. 5, pp. 672-693.

Mann, L, Dall'Alba, G \& Radcliffe, D 2007. 'Using phenomenography to investigate different ways of experiencing sustainable design', in Proceedings of the American Society for Engineering Education Annual Conference and Exposition, n.p. retrieved 22 October 2018, https://peer.asee.org/using-phenomenography-to-investigate-different-ways-ofexperiencing-sustainable-design.pdf

Marsden, N \& Haag, M 2016, 'Stereotypes and politics: reflections on personas', in Proceedings of the 2016 CHI Conference on Human Factors in Computing Systems, San Jose, CA, pp. 40174031.

Marton, F 1981, 'Phenomenography-describing conceptions of the world around us,' Instructional Science, vol. 10, no. 2, pp. 177-200.

Marton, F 1986, 'Phenomenography-a research approach to investigating different understandings of reality', Journal of Thought, vol. 21, no. 3, pp. 28-49.

Massanari, AL 2010, 'Designing for imaginary friends: information architecture, personas and the politics of user-centered design', New Media \& Society, vol. 12, no. 3, pp. 401-416.

Matthews, T, Judge, T \& Whittaker, S 2012, 'How do designers and user experience professionals actually perceive and use personas?'. in Proceedings of the 2012 SIGCHI Conference on Human Factors in Computing Systems, Austin Texas, pp. 1219-1228.

McCosker, H, Barnard, A \& Gerber, R 2003, 'Phenomenographic study of women's experiences of domestic violence during the childbearing years', Online Journal of Issues in Nursing, vol. 7, no. 1, pp. 1-13.

Mulder, S, \& Yaar, Z 2006, The user is always right: A practical guide to creating and using personas for the web, New Riders, Berkeley CA.

Muller, M 2014, 'Curiosity, Creativity, and Surprise as Analytic Tools: Grounded Theory Method,' in J Olson \& W Kellogg (eds), Ways of Knowing in HCI, Springer, New York NY.

Nielsen, L 2003, 'Constructing the User', in Proceedings of Human Computer Interaction International - HCII2003, Crete, pp. 430-434.

Pruitt, J \& Grudin, J 2003, 'Personas: practice and theory', in Proceedings of the 2003 Conference on Designing for User Experiences, pp. 1-15.

Putnam, RD 2001, Bowling alone: The collapse and revival of American community, Simon \& Schuster, New York NY.

Rogers, Y, Sharp, H \& Preece, J 2007, Interaction design: beyond human-computer interaction, John Wiley \& Sons, London.

Rönkkö, K, Hellman, M, Kilander, B \& Dittrich, Y 2004, 'Personas is not applicable: local remedies interpreted in a wider context', in Proceedings of the Eighth Conference on Participatory 
Design: Artful integration: interweaving media, materials and practices, Toronto, vol. 1, pp. 112-120.

Rosenfeld, L \& Morville, P 2002, Information architecture for the world wide web, O'Reilly, London.

Sciannanamblo, M, Wilson, A, Lyle, P, Teli, M, De Paoli, S, Bassetti, C \& De Angeli, A 2018, 'Codesigning for common values: creating hybrid spaces to nurture autonomous social collaboration', Co-Design, submitted.

Schuler, D \& Namioka, A (eds) 1993, Participatory design: Principles and practices, Lawrence Erlbaum, London.

Sjöström, B \& Dahlgren, LO 2002, 'Applying phenomenography in nursing research', Journal of Advanced Nursing, vol. 40, no. 3, pp. 339-345.

Strauss, A \& Corbin, JM 1990, Basics of qualitative research: Grounded theory procedures and techniques, SAGE Publications, Los Angeles CA.

Svensson, L 1997, 'Theoretical foundations of phenomenography', Higher Education Research \& Development, vol. 16, no. 2, pp. 159-171.

Trigwell, K 2006, 'Phenomenography: An approach to research into geography education', Journal of Geography in Higher Education, vol. 30, no. 2, pp. 367-372.

Turner, P, \& Turner, S 2011, 'Is stereotyping inevitable when designing with personas?', Design Studies, vol. 32, no. 1, pp. 30-44.

Vogiatzi, M, Keratidis, C, Schinas, M, Diplaris, S, Yümlü, S, Forbes, P \& Symeonidou, M 2017, 'The STEP Project: Societal and Political Engagement of Young People in Environmental Issues', in I Kompatsiaris, J Cave, A Satsiou, G Carle, A Passani, E Kontopoulos, S Diplaris \& D McMillan (eds), Proceedings of the International Conference on Internet Science, Thessaloniki, pp. 148-156.

Weber, M 1978, Economy and society: An outline of interpretive sociology, University of California Press, Berkeley CA.

Wilson, AN, Sachy, M, Ottaviano, S, De Paoli, S \& De Pellegrino, F 2017, 'PIE News Deliverable D3.1 User Research Report and Scenarios', retrieved 31 March 2018 http://pieproject.eu/2017/07/03/d3-1-user-research-report-and-scenarios/

Yates, C, Partridge, HL \& Bruce, CS 2012, 'Exploring information experiences through phenomenography', Library and Information Research, vol. 36, no. 112, pp. 96-119. 